\title{
Article \\ Mechanical Property Studies of Nanolayered Polymer Membranes
}

\author{
Hui Shen ${ }^{1, *}$, Ahmed Abdel-Mohti ${ }^{2}$ \\ 1 Mechanical Engineering Department, Ohio Northern University, Ada, OH 45810, USA \\ 2 Civil Engineering Department, Ohio Northern University, Ada, OH 45810, USA; a-abdel-mohti@onu.edu \\ * Correspondence: h-shen@onu.edu; Tel.: +1-419-772-2380
}

Academic Editor: name

Received: date; Accepted: date; Published: date

\begin{abstract}
Nanolayered polymer membranes, which have biomimicking layered structures, have been developed in recent years. The unique microstructures allow the membranes to have many potential applications. To facilitate the application of the membranes, the understandings of mechanical properties of the pristine and aged membranes are needed for the short and long-term applications. The current study focuses on the study of the relationship between the microstructure of the membrane and the mechanical properties including stiffness, strength, and ductility. The effect of the microstructure on the long-term application has been evaluated by thermal aging. The nanolayered polymer membranes have been subjected to thermal aging at various temperatures for different time frames. It has been found that the microstructure parameters, such as layer thickness, have great effect on the mechanical properties and thermal aging resistance. The thinner the layer of the membrane is, the better the strength and thermal aging resistance are.
\end{abstract}

Keywords: nanolayered polymer membranes; microstructures; mechanical properties

\section{Introduction}

Many natural biological systems have layered microstructures. For example, the lens of the human eye is made up of roughly 22,000 very fine layers. Such a laminar structure, forming discontinuous tiny segments of rays, can offer better optical properties than manmade lenses [1]. The turtle shell, composed of layered structure, has a Yong's modulus of approximately 20 GPa [2]. To learn from the biology systems, multilayered polymers have been developed by coextrusion process of polymeric systems [3], which was developed by the Dow Chemical Company in the 1970s firstly [4-8]. The mechanism of coextrusion is that two polymer components are stacked and fed into multiplying system and finally form a layered membrane. With the development of the coextrusion techniques, polymer membranes have been developed with layers in nano scale, which have a truly biomimetic nature $[9,10]$. The unique microstructures allow the membranes many potential applications. To facilitate the application of the membranes, the understandings of mechanical properties of the pristine and aged membranes are needed for the short and long-term applications. The current study focuses on the study of the relationship between the microstructure of the membrane and the mechanical properties including stiffness, strength, and ductility. The effect of the microstructure on the long-term application has been evaluated by thermal aging. The nanolayered polymer membranes have been subjected to thermal aging at various temperatures for different time frames. It has been found that the microstructure parameters, such as layer thickness, have great effect on the mechanical properties and thermal aging resistance. 


\section{Experimental Materials and Methods}

The composition of polymer membranes in the current study is 50 vol \% poly(methyl methacrylate) (PMMA) and $50 \mathrm{vol} \%$ polycarbonate (PC). The thickness of the membranes is $5 \mu \mathrm{m}$ with layer thickness ranging from 31 to $1984 \mathrm{~nm}$. The effect of the layer thickness on the mechanical properties and resistance to thermal aging has been studied. Static tension tests have been carried out on the samples according to the ASTM D882. Based on the tensile stress-strain curves, the modulus of elasticity, tensile strength, and the fracture strain were obtained for comparison. Samples are approximately 6 in $(152 \mathrm{~mm})$ long and 0.2 in $(5 \mathrm{~mm})$ wide, with the gauge length of 4 in $(102 \mathrm{~mm})$. The modulus of elasticity, tensile strength and fracture strain of membranes were studied at aging time up to 6 weeks ( 42 days) at $100{ }^{\circ} \mathrm{C}$ and $125{ }^{\circ} \mathrm{C}$ aging temperatures. About 10 samples for each type of membrane and for each aging time were used for the test.

\section{Results and Discussion}

\subsection{Layer Thickness}

The average results of the modulus of elasticity for the pristine membranes and membranes aged at $100{ }^{\circ} \mathrm{C}$ for 42 days are listed in Table 1 . The effect of the layer thickness can be seen from the table. As the layer thickness decreased to the level of 124 and $31 \mathrm{~nm}$, compared to the layer thicknesses of $496 \mathrm{~nm}$ and $1984 \mathrm{~nm}$, the modulus of elasticity increased by approximately 1.5 times. This difference can be explained from the view of microstructure. PC and PMMA are thermal plastic polymers with semicrystalline structures. As the two materials are coextruded together, the border between the layers imposes confinement to the layer and therefore the molecular chains in the layer are more aligned, which increases the Von der Waals force between the chains. The higher alignment of the molecular chains also plays a role in the thermal aging resistance. After 42 days aging, the modulus increases with the aging time to reach about $56.5 \%$ and $65.6 \%$ increase for layer thicknesses of $496 \mathrm{~nm}$ and $1984 \mathrm{~nm}$, but decreases for the membranes with $31 \mathrm{~nm}$ and $124 \mathrm{~nm}$ layer thickness by $26.3 \%$ and $2.6 \%$, respectively. It can be concluded that the property is relatively stable for the membranes with thinner layer thickness.

Table 1. The modulus of elasticity varies with aging time and layer thickness.

\begin{tabular}{cccc}
\hline Layer Thickness (nm) & 0 Day Aging (ksi) & 42 Day Aging (ksi) & Difference (\%) \\
\hline 1984 & 195 & 323 & +65.6 \\
496 & 184 & 288 & +56.5 \\
124 & 343 & 334 & -2.6 \\
31 & 308 & 389 & -26.3 \\
\hline
\end{tabular}

The average tensile strength for the pristine membranes and membranes aged at $100{ }^{\circ} \mathrm{C}$ for 42 days are listed in Table 2. The trend of strength does not change significantly with layer thickness and aging time for all the membranes. This may be due to the fact the as the membrane is subject to tension, the molecular chains get straightened before finally break. The strength will be dependent on the strength of the covalent bones in the molecular chains, which is not affected by the initial alignment of the chains in the pristine material at this temperature $\left(100^{\circ} \mathrm{C}\right)$.

Table 2. The tensile strength varies with aging time and layer thickness.

\begin{tabular}{cccc}
\hline Layer thickness (nm) & 0 Day Aging (ksi) & 42 Day Aging (ksi) & Difference (\%) \\
\hline 1984 & 10.83 & 10.17 & -6.1 \\
496 & 9.30 & 9.81 & 5.5 \\
124 & 9.96 & 11.08 & 11.2 \\
31 & 10.58 & 11.41 & 7.8 \\
\hline
\end{tabular}

The average fracture strain for the pristine membranes and membranes aged at $100{ }^{\circ} \mathrm{C}$ for 42 days are listed in Table 3. The trend of ductility decreases with aging time for all of the membranes 
no matter what the layer thickness is. The ductility was measured by the amount of strain that the material could sustain before it fractures. The thermal aging conditions might destroy the covalent bonds in the molecular chains of the polymers.

Table 3. The fracture strain varies with aging time and layer thickness.

\begin{tabular}{cccc}
\hline Layer thickness (nm) & 0 Day Aging & 42 Day Aging & Difference (\%) \\
\hline 1984 & 0.064 & 0.039 & -39.1 \\
496 & 0.048 & 0.045 & -6.3 \\
124 & 0.061 & 0.045 & -26.2 \\
31 & 0.047 & 0.034 & -27.7 \\
\hline
\end{tabular}

\subsection{Aging Temperature}

The effect of temperature on modulus of elasticity was studied for the membrane with $31 \mathrm{~nm}$ thick layer at temperatures of $100{ }^{\circ} \mathrm{C}$ and $115^{\circ} \mathrm{C}$ for up to 4 weeks aging. To observe the trend, all of the data were normalized by the pristine material properties. The moduli of elasticity of the aging are shown in Table 4, from which it can be observed that the trend for the stiffness increase for the membrane at $100{ }^{\circ} \mathrm{C}$, but relatively stable at $115{ }^{\circ} \mathrm{C}$. This can be explained that at $100{ }^{\circ} \mathrm{C}$, the membranes have been annealed and the percentage of crystallinity might increase over aging and therefore the modulus of elasticity increased. At $115^{\circ} \mathrm{C}$, the relatively high temperature thermal aging condition destroys the covalent bonds in the molecular chains of the polymers which compromises the effect of the annealing.

Table 4. Modulus of elasticity of the membrane with $31 \mathrm{~nm}$ thick layer aged at temperatures of $100{ }^{\circ} \mathrm{C}$ and $115^{\circ} \mathrm{C}$.

\begin{tabular}{cccccc}
\hline Temperature $\left({ }^{\circ} \mathbf{C}\right)$ & 0 Day Aging & 7 Day Aging & 14 Day Aging & 21 Day Aging & 28 Day Aging \\
\hline 100 & 1.00 & 1.42 & 1.18 & 1.26 & 1.39 \\
115 & 1.00 & 1.01 & 0.84 & 0.90 & 0.99 \\
\hline
\end{tabular}

The tensile strength of the aging are shown in Table 5, from which it can be observed that the trend of the tensile strength with aging time is similar to that of the modulus of elasticity. The tensile strength increases for the membranes at $100{ }^{\circ} \mathrm{C}$ with aging time, but decreases at $115{ }^{\circ} \mathrm{C}$ with aging time. This can be owing to at $100{ }^{\circ} \mathrm{C}$, the percentage of crystallinity is increased over aging time, but at $115^{\circ} \mathrm{C}$, the relatively high temperature thermal aging condition destroys the covalent bonds in the molecular chains of the polymers.

Table 5. Tensile Strength of the membrane with $31 \mathrm{~nm}$ thick layer aged at temperatures of $100{ }^{\circ} \mathrm{C}$ and $115^{\circ} \mathrm{C}$.

\begin{tabular}{cccccc}
\hline Temperature $\left({ }^{\circ} \mathbf{C}\right)$ & 0 Day Aging & 7 Day Aging & 14 Day Aging & 21 Day Aging & 28 Day Aging \\
\hline 100 & 1.00 & 1.10 & 1.21 & 1.10 & 1.05 \\
115 & 1.00 & 0.88 & 0.97 & 0.88 & 0.84 \\
\hline
\end{tabular}

The fracture strains for both the aging temperatures are shown in Table 6. As all of the membranes lost ductility during aging, the higher the temperature and the longer the aging time, the more brittle the membranes become, which indicated the greater degradation of chemical bonds in the molecular chains. It can be observed that at $115^{\circ} \mathrm{C}$, the membranes only keep about $5 \%-6 \%$ of the original ductility after 14 days aging.

Table 6. Modulus of elasticity of the membrane with $31 \mathrm{~nm}$ thick layer aged at temperatures of $100{ }^{\circ} \mathrm{C}$ and $115^{\circ} \mathrm{C}$.

\begin{tabular}{cccccc}
\hline Temperature $\left({ }^{\circ} \mathrm{C}\right)$ & 0 Day Aging & 7 Day Aging & 14 Day Aging & 21 Day Aging & 28 Day Aging \\
\hline 100 & 1 & 0.52 & 0.73 & 0.67 & 0.52 \\
115 & 1 & 0.24 & 0.05 & 0.07 & 0.06 \\
\hline
\end{tabular}




\section{Conclusions}

In this paper, the relationship between the microstructure of the membrane and the mechanical properties has been studied. The effect of the microstructure on the long-term application has been evaluated by thermal aging. It has been found that as the layer thickness reduces to 124 and $31 \mathrm{~nm}$, the modulus of elasticity increased and the trend is relatively stable for the membranes with thinner layer thickness. The tensile strength for the pristine membrane and membrane aged at $100{ }^{\circ} \mathrm{C}$ for 42 days does not change with layer thickness and aging time significantly. As for the temperature effect, the trend for the stiffness and strength increase for the membrane at $100{ }^{\circ} \mathrm{C}$, but relatively stable or decrease at $115^{\circ} \mathrm{C}$. This can be explained that at $100{ }^{\circ} \mathrm{C}$, the membranes have been annealed and the percentage of crystallinity increased over aging time and therefore the modulus of elasticity increased. At $115^{\circ} \mathrm{C}$, the relatively high temperature thermal aging conditions destroy the covalent bonds in the molecular chains of the polymers which compromise the effect of the annealing. All of the membranes lost ductility during aging, the higher the temperature and the longer the aging time, the more brittle the membranes become over aging. At $115{ }^{\circ} \mathrm{C}$, the membranes only keep about $5 \%-6 \%$ of the original ductility.

Acknowledgments: The authors acknowledge the financial support of the National Science Foundation through Grant Number DMR-0423914 and the materials provided by Dr. Eric Baer at Case Western Reserve University.

\section{References}

1. Kopeika, N.S. A System Engineering Approach to Imaging; Spie Optical Engineering Press: Bellingham, WA, USA, 1998.

2. Rhee, H.; Horstemeyer, M.F.; Hwang, Y.; Lim, H.; Kadiri, H.E.; Trim, W. Experiments-Structure and Mechanical Properties of the Turtle Shell. Available online: https://icme.hpc.msstate.edu/ mediawiki/index.php/Experiments Structure_and_Mechanical_Properties_of_the_Turtle_Shell. (accessed on 9 April 2016).

3. Ponting, M.; Hiltner, A.; Baer, E. Polymer Nanostructures by Forced Assembly: Process, Structure, and Properties. Macromol. Symp. 2010, 294, 19-32.

4. Schrenk, W.J.; Chisholm, D.S.; Cleereman, K.J.; Alfrey, Jr, T. Method of Preparing Multilayer Plastic Articles. U.S. Patent 3,565,985, 23 February 1971.

5. Alfrey, T.; Schrenk, W. Highly Reflective Thermoplastic Bodies for Infrared, Visible or Ultraviolet Light. U.S. Patent 3,711,176, 16 January 1973.

6. Schrenk, W.J. Apparatus for Multilayer Coextrusion of Sheet or Film. U.S. Patent 3,884,606, 20 May 1975.

7. Schrenk, W.J.; Shastri, R.K.; Ayres, R.F.; Gosen, D.J. Interfacial Surface Generator. U.S. Patent 5,094,788, 10 March 1992.

8. Ravi, R.; Schrenk, W.J.; Wheatley, J.A. Coextrusion of Multilayer Articles Using Protective Boundary Layers and Apparatus Therefor. U.S. Patent 5,269,995, 14 December 1993.

9. Ania, F.; Baltá-Calleja, F.J.; Henning, S.; Khariwala, D.; Hiltner, A.; Baer, E. Study of the Multilayered Nanostructure and Thermal Stability of PMMA/PS Amorphous Films. Polymer 2010, 51, 1805-1811.

10. Ania, F.; Puente, O.I.; Baltá-Calleja, F.J.; Roth, S.; Khariwala, D.; Hiltner, A.; Baer, E.; Roth, S.V. Ultra-smallangle X-ray Scattering Study of PET/PC Nanolayers and Comparison to AFM Results. Macromol. Chem. Phys. 2008, 209, 1367-1373.

(C) 2016 by the authors; licensee MDPI, Basel, Switzerland. This article is an open access article distributed under the terms and conditions of the Creative Commons by Attribution (CC-BY) license (http://creativecommons.org/licenses/by/4.0/). 